\title{
A Second Look At Faculty Development and the Second Sex
}

\section{Michele Fisher and Winifred E. Anderson}

Description: The workshop begins by identifying the needs and interests of women in academia as perceived by the workshop participants. Workshop facilitators provide information from the literature and their personal experiences on major issues and descriptions of the successes and pitfalls of various support programs. Participants then work on solutions to common problems and issues described in a set of case studies. The ensuing discussion concludes with the generation of two lists, one identifying needs and problems of academic women, and the other containing suggestions for remedies and actions, particularly at an institution-wide level. The final activity is distribution of literature and collection of names and addresses to facilitate further communication among participants.

\section{Length: $\quad 11 / 2$ (or 2 ) hours}

Participants: Faculty development personnel, academic administrators, department chairpersons, faculty members, and/or graduate students

Objectives: 1. Raise consciousness regarding the special problems and needs of women in academia

2. Identify or generate solutions to those problems and needs

3. Build the energy, confidence, and enthusiasm required to put such solutions into practice. 
4. Share information regarding successes and failures of past efforts

5. Initiate a new support network and establish a mechanism for future information exchanges

Materials: Case studies (seven examples are included in this outline) Select bibliography of books/articles example included) Handouts providing information on existing groups, activities, etc. Two large newsprint pads and stands or chalkboard. Registration list including addresses and/or telephone numbers.

\section{Schedule and Content}

I. Opening and Background Information

20 (30) minutes

A. Facilitator presentation:

Introduction of workshop, facilitator(s), and session objectives

Brief description of workshop format

B. Facilitator elicits information from participants:

"How would you describe the environment for women in the academic institution/group you represent?"

"What do you perceive as major concerns or interests in this area?"

C. Facilitator presentations:

1. Reasons for interest in topic of support for academic women

a. Data on hiring, promotion, etc.

b. Women as source of new energy and creativity

2. Description of the development of a campus support system; identification of efforts that were notable successes or failures

II. Case Studies

30 (50) minutes
A. Facilitator:
5 minutes

1. Divides participants into groups of 2 or more. Members of each group are given copies of a case study. 
2. Instructs each group to read the case study and develop proposals for dealing with the specific case and, if possible, for actions that would respond to the situation on an institution-wide basis. [Each group is given a different case study. There should be 3-5 groups, depending upon the amount of time allotted for discussion of the case studies.]

B. Small group work 10 minutes

C. Reports to the plenary session 15 (35) minutes

All participants are reassembled. From each group, one person reads the case study aloud. A second spokesperson presents the group's proposals. Discussion and comment from all participants are encouraged as time allows.

III. Summary

30 minutes

A. Facilitator generates two lists from participant contributions:

1. "In summary, what have we identified as major issues or concerns for women in academic environments?"

2. 'Let's see if we can now generate a check list of specific programs and actions that we would recommend to persons or institutions interested in addressing those issues."

IV. Conclusion

10 minutes

A. Facilitator:

1. Describes available literature and invites participants to browse and take away what they wish

2. Indicates plan to collect and distribute names and addresses/telephone numbers to facilitate further contacts among participants

3. Makes final remarks 


\section{Case Studies:}

\section{Number 1}

You are consulting with a teaching assistant who has consistently received low student evaluations. She has been warned that unless they improve she will not be asked to teach again, and it is her main source of income. She is convinced that her low evaluations are related to the fact that she is the only woman teaching in the department, her students are almost all male, and she lacks the "hands-on" knowledge many of her peers and professors have. Your own observations, based on personal visits and videotapes, reveal that her interpretation seems at least partly justified. Aside from a certain lack of self-confidence and a rather low-key style, she exhibits good teaching skills.

What strategies do you try in your consultation? How do you address her frustration that is mainly her gender that is affecting an otherwise potentially successful career?

\section{Number 2}

Over the past few years, a group of undergraduate, graduate, and young faculty women on your campus have been drawing attention to circumstances they perceive as sexist. Examples have ranged from the lack of child care facilities, to the dismissal of a popular feminist instructor, to the dearth of female administrators. The college president has finally appointed a Task Force on Women to research the relevant issues and you have been asked to be on it. After the first few meetings you get the strong feeling that the Task Force was created primarily for the sake of appearances and that most of the (male) administrators have little or no empathy for women's issues.

What strategies and activities would you recommend to your fellow Task Force members? What do you perceive as potential pitfalls and how would you avoid them?

\section{Number 3}

During a private, social conversation you learn from a female faculty member that she is feeling extremely frustrated and unhappy 
over the slowness of her promotion progress. It seems that she and her husband joined the faculty at the same time and have similarly outstanding research and teaching records, but he has been receiving accelerated promotions and her progress has been minimal. She is the only woman in her department. Recently he has heard the comment that some of the senior faculty members see no urgency in promoting her since there is already a full professorship in the family. (i.e. her husband's) and there is little likelihood that she will be inclined to go elsewhere.

Is there anything you as a colleague can or should do to help her? What actions might be useful on a long-term, campuswide basis to reduce sexual bias in promotion/tenure decisions?

\section{Number 4}

A minority graduate student has come to consult with you about the results of a student survey you conducted in her class. It soon becomes apparent that what she really wants to talk about is her total (mostly unpleasant) experience as a graduate in your university. She says she is on her third major advisor, is having difficulty developing a productive research project of which the advisor approves, and has been told by two faculty members that since she seems unable to find a compatible advisor and a good research project she is wasting her time in graduate school. She is obviously not comfortable with her third advisor either, but is afraid that changing again will damage her reputation beyond repair. She seems very determined to complete a graduate degree. She is aware that her personal style is not particularly smooth and self-confident and mentions that she has taken an assertiveness class to help remedy the situation.

How would you counsel her? How can it be determined whether this is an instance of faculty resistance to a non-traditional student or a case of a student making a poor career choice? Is this determination appropriate for you to make as a faculty development consultant or should you refer her to someone else? If so, to whom? 


\section{Number 5}

During an informal meeting of faculty women you are surprised to hear several women from predominantly male departments complain that by far the greatest amount of sexual bias they encounter comes from women on the departmental secretarial staff. For example, typists who are often "too busy" to type letters and exams for women faculty, have never yet been known to turn down a typing request from a male faculty member. Differences are also apparent in the level of professionalism used in conversation and in taking telephone messages. Female faculty (especially young ones) are referred to by their first names; males are called "Professor Smith" etc. One female faculty member found that when she was out of her office, callers were told in an off-hand tone that "She isn't there and I have no idea where she is or when she will be back." She inquired among her male colleagues and found that the treatment their callers received was remarkably different -the professor's schedule was explained and messages were taken in a very professional manner.

How would you suggest resolving such problems? What pitfalls do you see and how would you avoid them? What long-term, campuswide actions might be helpful?

\section{Number 6}

You have been asked to organize a workshop for faculty members who are about to teach an innovative humanities sequence. For the most part you will be attempting to combine an intensive review of selected content with recommendations on effective teaching techniques. The Women's Research group on campus has heard about the workshop and asked that a session on "gender assumptions" be included, discussing, for example, how standard works should/could be reinterpreted once gender assumptions are re-examined. It is the group's contention that since this is a new and innovative sequence, it has a special obligation to consider the research and the theoretical challenges that Women's Studies has developed in relevant fields. The research group is willing to assist you in the choice of speakers and format for the session. 
Do you go along with the group's recommendations? If so, what steps do you take to maximize the positive impact that this session will have? What problems do you anticipate and what can you do to minimize them? If you do not agree to their recommendations, what do you propose instead?

\section{Number 7}

Because you work with graduate teaching assistants, you are asked to a meeting on improving the quality of graduate student life. One of the graduate students suggests that he and his peers need more social supports. A woman graduate student agrees and says that the problem is particularly acute for women who are in departments that are mainly male. One of several department chairs there immediately retorts that even if social isolation exists, it is not an important issue; the "cream always rises to the top," that is, the best always survive. He further insinuates that affirmative action programs at both the faculty and graduate level have brought in the unfit and intellectually inferior. The remarks are challenged by several participants, but the line of discussion is cut off by the committee chair as he sees emotions rising.

Later you are asked how, if at all, the department chair should be approached regarding his affirmative action attitude and its consequences for women (and minority) faculty and students in his department. What would you advise? Are there worthwhile actions that could be taken at a campuswide level that would help change such negative attitudes?

\section{Select Bibliography:}

Astin, Helen S., Career profiles of women doctorates, in Academic Women on the Move, ed. by Alice S. Rossi and Ann Calderwood, New York: Russell Sage Foundation, 1973, 139-161.

Bernard, Jessie, Academic Women, New York: New American Library, 1964.

Gappa, J. and B. Uehling, Women in Academe: Steps to Greater Equality; Research Report 1. Washington, D.C.: American Association for Higher Education, 1979.

Howe, Florence and Carol Ahlum, Women's studies and social change, in Rossi and Calderwood (1973), 393-423.

Justice, David O., The future of faculty development, POD Quarterly 1 (1979), 33-42. 
Lazarus, Barbara and Martha Tolpin, Engaging junior faculty in career planning: alternatives to the exit interview, Current Issues in Higher Education 2 (1979), 29-32.

Loewenstein, Sophie Freud, The passion and challenge of teaching, Harvard Educational Review 50 (1980), 1-12.

Rumbarger, Margaret L., Internal remedies for sex discrimination in colleges and universities, Rossi and Calderwood (1973), 425-438.

Sandler, Bernice Resnick, You've come a long way, maybe-or why it still hurts to be a woman in labor, Current Issues in Higher Education 4 (1979), 11-14.

Sassen, Georgia, Success anxiety in women: A constructivist interpretation of its source and its significance, Harvard Educational Review 50 (1980), 13-24.

Sharpham, John and Lanny Moreau, Focusing faculty development: Targeting, POD Quarterly 2 (1980), 92-100.

Spencer, Mary L. and Eva F. Bradford, Status and needs of women scholars, in Handbook for Women Scholars: Strategies for Success, ed. by Monika Kehoe, U.S. Department of Education, 1980.

White, Barbara A., Up from the podium: Feminist revolution in the classroom, Female Studies 4 (1971), 28-34.

Women on Campus: The unfinished Liberation, New Rochelle N.Y.: Change Magazine, 1975. 